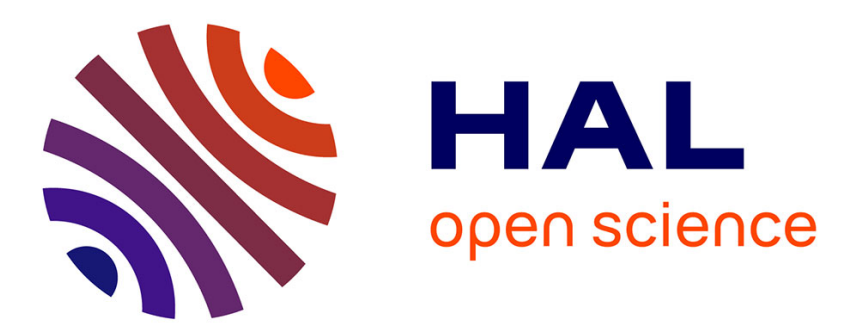

\title{
A methodology for the 3D stress analysis and the design of layered sheet metal forming tools joined by screws
}

\author{
M. Oudjene, Jean-Louis Batoz, Luc Penazzi, Frédéric Mercier
}

\section{To cite this version:}

M. Oudjene, Jean-Louis Batoz, Luc Penazzi, Frédéric Mercier. A methodology for the 3D stress analysis and the design of layered sheet metal forming tools joined by screws. Journal of Materials Processing Technology, 2007, 189 (1-3), pp.334-343. 10.1016/j.jmatprotec.2007.02.018 . hal-01717323

\section{HAL Id: hal-01717323 \\ https://hal.science/hal-01717323}

Submitted on 7 Nov 2018

HAL is a multi-disciplinary open access archive for the deposit and dissemination of scientific research documents, whether they are published or not. The documents may come from teaching and research institutions in France or abroad, or from public or private research centers.
L'archive ouverte pluridisciplinaire HAL, est destinée au dépôt et à la diffusion de documents scientifiques de niveau recherche, publiés ou non, émanant des établissements d'enseignement et de recherche français ou étrangers, des laboratoires publics ou privés. 


\title{
A methodology for the 3D stress analysis and the design of layered sheet metal forming tools joined by screws
}

\author{
M. Oudjene ${ }^{\text {a,* }}$, J.-L. Batoz ${ }^{\text {b }}$ L. Penazzi ${ }^{\text {c }}$, F. Mercier $^{\text {a }}$ \\ ${ }^{a}$ ERMeP, GIP-InSIC, 27 rue d'Hellieule, 88100 Saint-Dié-des-Vosges, France \\ ${ }^{\mathrm{b}}$ Université de Technologie de Compiègne, BP 20529, 60205 Compiègne Cedex, France \\ ${ }^{\mathrm{c}}$ CROMeP, Ecole des Mines d'Albi-Carmaux, 81013 Albi Cedex 9, France
}

\begin{abstract}
In sheet metal forming industry, several experimental trials have been carried out successfully in the last 10 years, to demonstrate the feasibility of layered forming tools, by various rapid prototyping techniques. Recently, a layered stamping punch, based on the Stratoconception ${ }^{\circledR}$ process, was produced in a Craft European project Fastool and used successfully to produce some parts. The layered punch was joined using several screws in addition to an epoxy adhesive. Numerical simulation softwares allowing for 3D stress analysis of the layered tools are needed to evaluate their deformation and the various solutions of an assembly system. In this context, the authors proposed and developed a simplified numerical procedure, based on two steps, for the 3D stress analysis of deformable tools (layered or not). In addition, an optimization procedure, based on design of experiments and response surface method, has been established in order to optimize the screw positions, which are crucial in the aim of achieving the required high strength and life duration of the assembly technique by screws. The results show the feasibility of the developed procedure in the context of industrial applications, the potential interest of the optimization of the screw positions is also outlined.
\end{abstract}

Keywords: FEM; Stamping process; Contact forces; Layered tooling; Rapid prototyping; Joining; Optimization

\section{Introduction}

In the context of sheet metal forming processes, traditional manufacturing of tools is both costly and time consuming. The global cost of stamped parts is highly influenced by the cost of the tools, depending on the volume production. Therefore, several new technologies, in particular rapid prototyping techniques based on the assemblage of steel sheets in layers have been developed in the last 10 years, in order to reduce cost and manufacturing delays of tools. In the last recent years, several developments on layered tools have been undertaken. Their production and their use on pressforming to produce stamped parts have been successfully explored. Several experimental studies dealing with layered forming tools are available in the technical literature [1-13]. None of these works, however, have examined the mechanical behaviour of the layered tools. In addition, the published papers and reports show that the research per-

\footnotetext{
* Corresponding author. Tel.: +33 3 29421821; fax: +33 329421825.

E-mail address: mourad.oudjene@insic.fr (M. Oudjene).
}

formed to date on layered forming tools has been only oriented towards the problems of their rapid and flexible production [13]. However, there is still a need for insight knowledge of the basic mechanisms of layered tools, in particular the joining technique.

Previous numerical analyses of forming process have concentrated exclusively on the behaviour of the workpiece (stress, strain, shape), mainly assuming rigid tools during analysis. At present a limited number of papers dealing with the elastic forming tools analysis have been published. Some numerical simulations of the deep-drawing by considering deformable tools, in relation with the wear behaviour, are available in $[14,15]$. Other studies of the deformable tools, in relation with the stress analysis can be found in $[12,16]$, but the works dealing with the mechanical behaviour of tools is mostly dealing with 2D situations (plane strain, axisymmetry), due to the complexity of the forming operation and computational aspects involved.

Stamping simulation taking into account the elastic deformation of tools during analysis is needed to evaluate the stresses and strains developed in the tools during the forming operation. In simulation of stamping parts with complex geometry, the incremental and dynamic explicit approach is, generally, used to 
deal with the contact conditions with friction. In this case, however, the mechanical behaviour of the tools cannot predicted with fairly good precision and in acceptable CPU times, if in the FE-analysis one considers the coupling between the blank forming and the linear elastic analysis of the tools [12].

In this paper, the authors proposed and developed a numerical procedure for the 3D stress analysis of the forming tools, in particular the layered ones. In the case of layered tools assembled by screws, an optimization procedure, based on the design of experiments and response surface method, has been established in order to optimize the screw positions as an attempt to improve the strength and the life duration of the joining technique. The results are presented in the context of an industrial benchmark test (layered stamping punch based on the Stratoconception ${ }^{\circledR}$ process [21]) assembled by screws in addition to an epoxy adhesive. In the present study, the adhesive thickness was not modelled in details. In fact the presence of the adhesive leads to local stress distribution effects which are neglected here. The authors would like also to mention that the present layered punch is only foreseen for prototyping and low volume production.

\section{Design principles of the layered punch}

Within the framework of the Craft European project Fastool, an industrial layered stamping punch (Fig. 1), with dimensions: $420 \mathrm{~mm} \times 220 \mathrm{~mm} \times 77 \mathrm{~mm}$, based on the Stratoconception ${ }^{\circledR}$ process, was produced by stacking $7 \mathrm{~mm}$-thick of $2 \mathrm{C} 45$ (XC48) steel sheets [21].

The main advantages of layered tools over those produced conventionally from 3D full machining of steel or cast iron block are their reduced manufacturing delays, their costs and their great adaptability (which still be greatly improved and optimized).

\subsection{The rapid prototyping process}

The Stratoconception ${ }^{\circledR}$ process consists in the slicing of the part by computing, into a set of elementary layers in which plugs are inserted. The elementary layers are identified and then directly manufactured by 2.5 axis rapid milling, or by 5

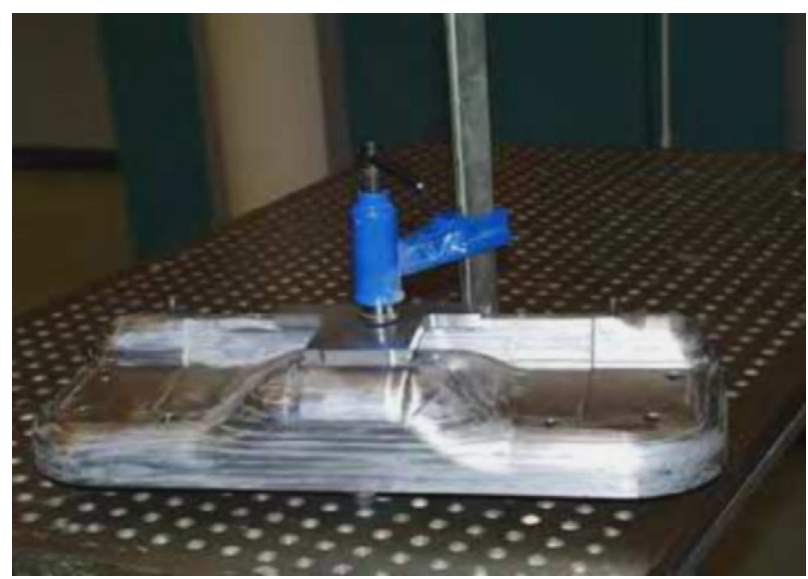

Fig. 1. Stamping layered punch. Source: CIRTES.

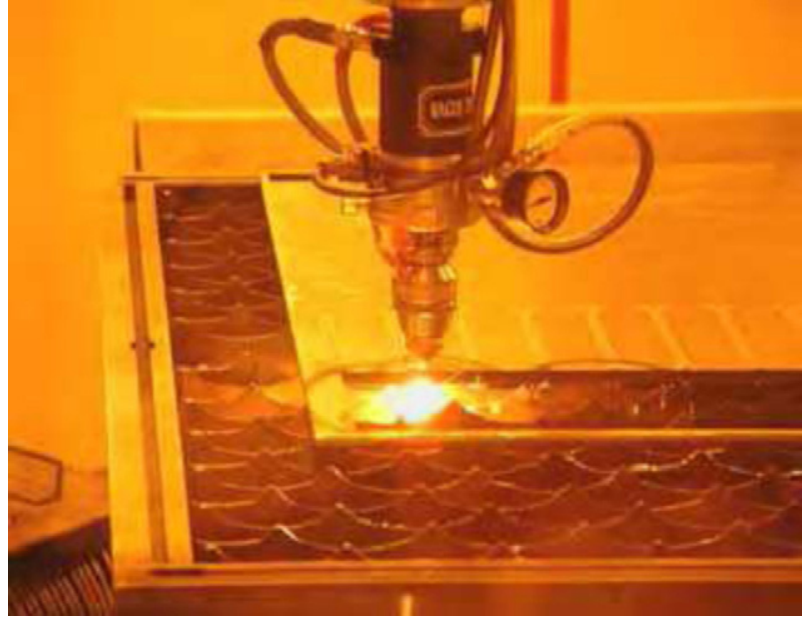

Fig. 2. Laser cutting of layers. Source: CIRTES.

axis machining from sheet material. These elementary layers are then fitted together in order to reconstruct the final product. The assembly of the layers by various techniques should be designed to support the mechanical constraints involved in working conditions $[9,21]$.

\subsection{Machining of the layers}

The different layers were directly machined with $7 \mathrm{~mm}$-thick of 2C45 (XC48) steel sheets using laser cutting and micromilling (Figs. 2 and 3) [9].

\subsection{The joining technique}

In practice, several joining techniques (such as brazing, sticking, riveting, screwing, bolting) can be suitable for rapid manufacturing techniques. In the layered punch, shown in Fig. 1, the layers were joined by several screws with $7 \mathrm{~mm}$ diameter after being positioned by four plugs with $6 \mathrm{~mm}$ diameter. In addition, the layered punch was reinforced using an epoxy adhesive

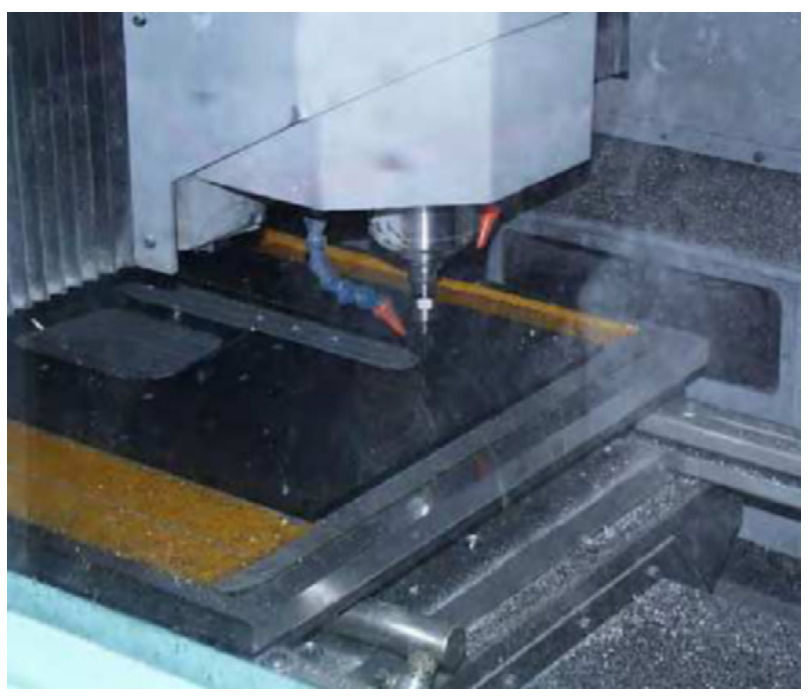

Fig. 3. Micro-milling of layers. Source: CIRTES. 


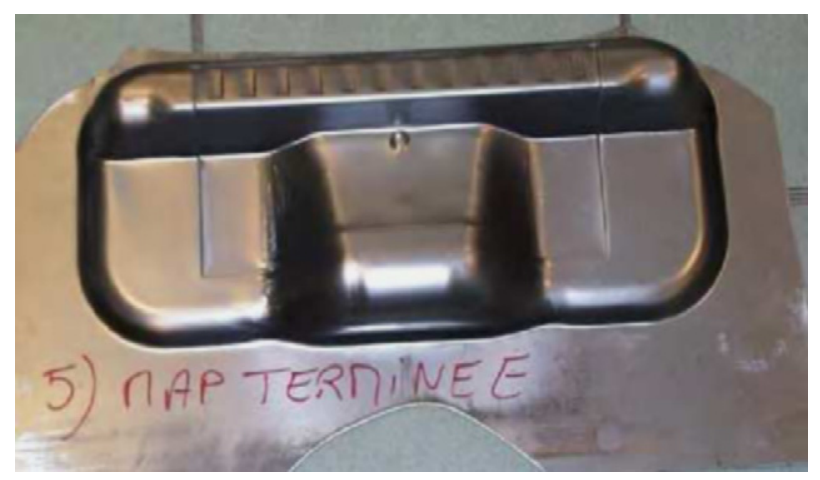

Fig. 4. Stamped part produced by the layered punch. Source: CIRTES.

with $0.1 \mathrm{~mm}$ of thickness, which was accommodated between layers.

The layered punch has been successfully used on pressforming to produce some stamped parts (Fig. 4) without any visual deterioration of the punch. However, the joining technique by screws is based only on simple practical rules and experience of designers and a number of complexities are still not fully understood or not modelled to date. Accordingly, the mechanical behaviour of the layered punch could be investigated, in particular the joining technique by screws, which is vital in designing layered tools.

\section{Elastic analysis of tools: some difficulties}

To properly analyse the behaviour of forming tools, it is justified to take into account their elastic deformation during the forming operation. However, at present, little research have been carried out on the stress analysis of tools. The stresses and strains induced in the forming tools during the forming operation are seldom computed in practice if not ignored in most of the today forming simulations.

The FE ABAQUS code is used to investigate the deep-drawing of a cylindrical cup (benchmark test of Numisheet'2002) [17], by considering elastic deformation of the cylindrical punch during analysis. The main purpose of this study is to examine the possibility to predict the behaviour of tools by coupling the simulation of the blank forming and the linear elastic analysis of the tools. The deep drawing parameters are shown in Fig. 5 [17].

The material data are: isotropic elasto-plastic material with hardening given by Hollomon's model with the following parameters: $n=0.27, K=539 \mathrm{MPa}$. Other sheet material properties are: $E=210 \mathrm{GPa}$ and $v=0.3$. The punch was assumed as isotropic and elastic material with the following properties: $E=210 \mathrm{GPa}$ and $\nu=0.3$ while the other tools (die, blankholder) were regarded as rigid. Coulomb friction model was adopted with frictional ratio $\mu=0.042$ as considered in Numisheet'2002 benchmark test [17].

Two-dimensional FE model was adopted using both static implicit and dynamic explicit approaches. All simulations have been carried out with a constant blankholder force of $70 \mathrm{kN}$ and for a punch stroke of $40 \mathrm{~mm}$.

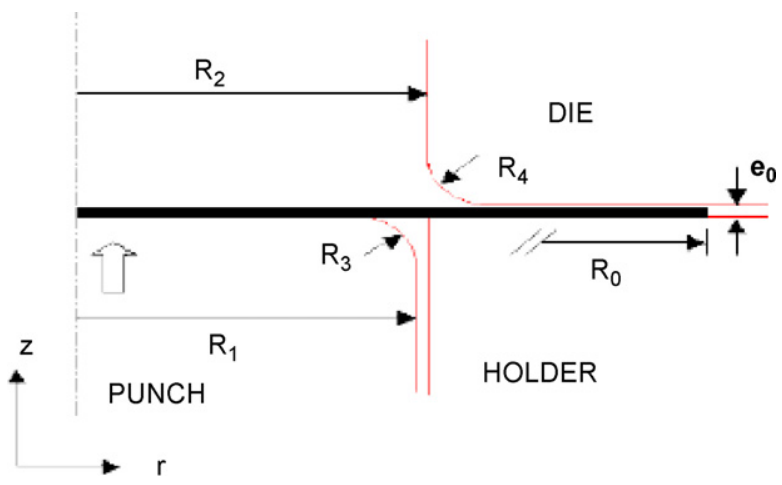

Fig. 5. Schematic illustration of the cylindrical cup [12,17]. $R_{1}=50 \mathrm{~mm}$; $R_{2}=51.25 \mathrm{~mm} ; R_{3}=9.5 \mathrm{~mm} ; R_{4}=7.0 \mathrm{~mm} ; R_{0}=105 \mathrm{~mm} ; e_{0}=1 \mathrm{~mm}$.

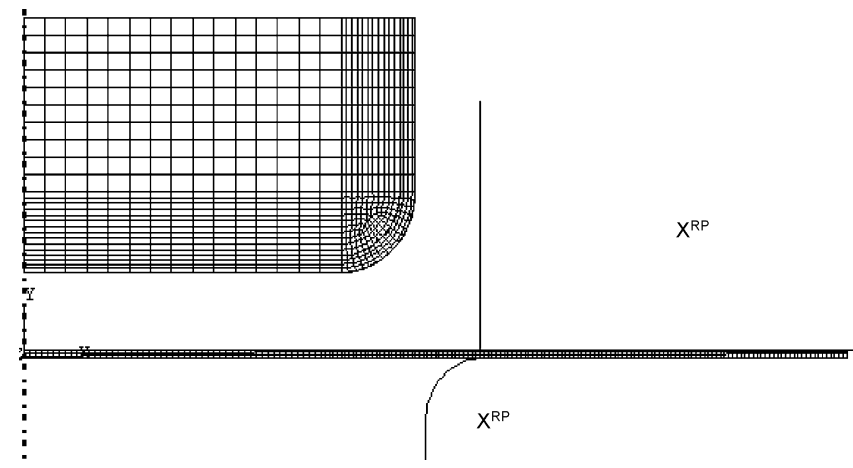

Fig. 6. 2D FE model with deformable punch [12].

\subsection{Static implicit model}

The blank was modelled by 4 and 270 axisymmetric elements with reduced integration (denoted CAX4R in ABAQUS) in the thickness and radial directions, respectively. The punch was modeled by 821 axisymmetric elements (denoted CAX4 in ABAQUS), see Fig. 6.

The results quality of the simulation procedure has been already evaluated in previous work [12], with regard to both the final part and the punch behaviour. The results showed good agreements with the literature ones regarding the workpiece. Fig. 7 shows the equivalent von-Mises stress distribution induced

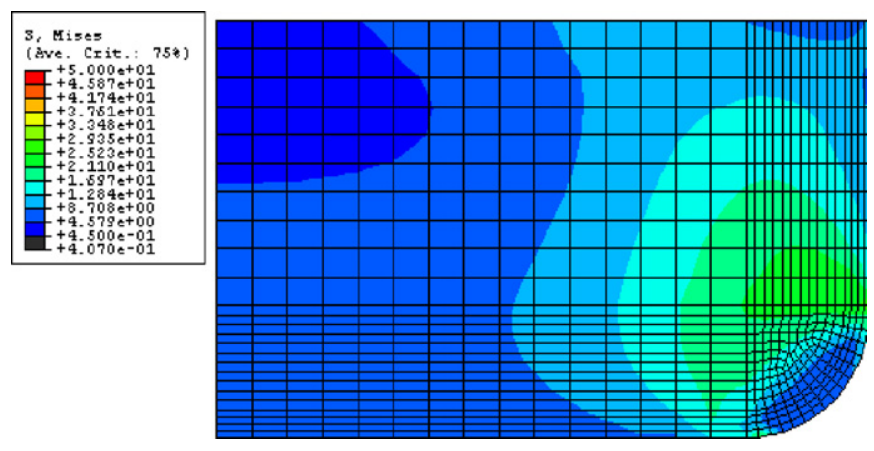

Fig. 7. Distribution of equivalent von-Mises stress in the punch at the end of the forming stage (static implicit scheme). 


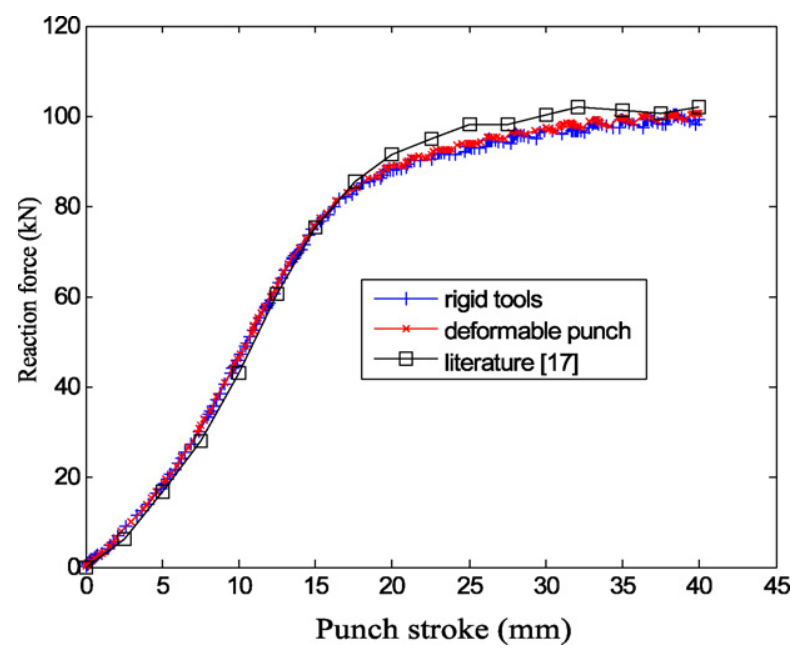

Fig. 8. Punch force-displacement curves: comparison between rigid and elastic tools (static implicit scheme).

in the punch at the end of the forming stage. The maximum computed equivalent von-Mises stress is around $35 \mathrm{MPa}$.

Furthermore, the contact forces (total punch reaction force) obtained by considering elastic deformation of the punch was compared to that obtained in the case of classical simulation by considering rigid tools (Fig. 8).

It can be seen that the elastic deformation of the tools do not have significant effect on the contact forces and it can be concluded that the deep drawing process contact force results are almost the same between rigid and elastic standard steel tools.

\subsection{Dynamic explicit model}

For the simulation of stamping parts with complex geometries, the dynamic explicit scheme is generally used because of the contact conditions with friction. The objective of this model is to check that we obtain the same results regarding the punch behaviour as with a static implicit scheme. The simulations were run using a classical punch velocity $V_{\mathrm{p}}=10 \mathrm{~m} / \mathrm{s}$. The effect of the mesh quality of the punch on the results with regard to the stress distribution was studied [12], but it was found that, when one uses a classical punch velocity of $10 \mathrm{~m} / \mathrm{s}$, it is impossible to obtain a good estimation of the stress developed in the punch (Fig. 9) compared to that obtained in the case of static implicit scheme (Fig. 7). The maximum amount of von-Mises stress developed in the punch is around $150 \mathrm{MPa}$. This is an important (numerical) result.

However, with the decrease of the punch velocity from 10 to $1 \mathrm{~m} / \mathrm{s}$, it became possible to obtain fairly good estimation of the stress distribution in the punch, based on the comparison between Figs. 7 and 10. In addition, the maximum value of the computed von-Mises stress is around $37 \mathrm{MPa}$. However, the CPU time has increased by a factor of 10 .

The use of a punch velocity of $1 \mathrm{~m} / \mathrm{s}$ allows also to obtain good estimation of the contact forces compared to that obtained in the case of rigid tools with a punch velocity of $10 \mathrm{~m} / \mathrm{s}$ (Fig. 11).From the above results, it can be concluded that general 3D stamping
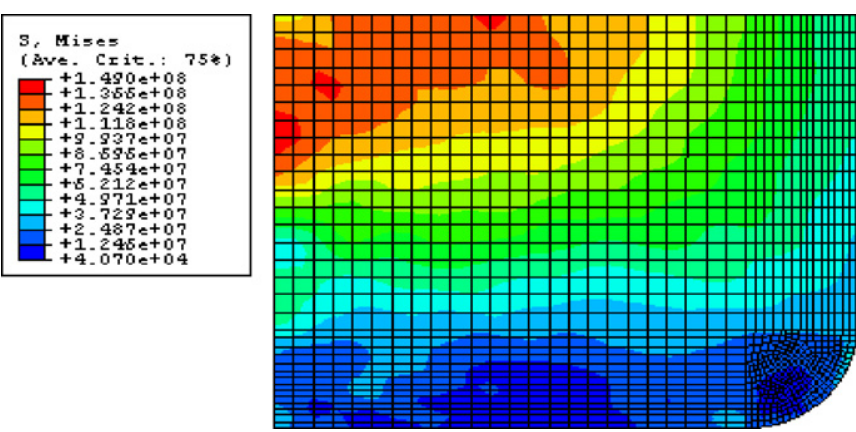

Fig. 9. Distribution of equivalent von-Mises stress in the elastic punch: case where $V_{\mathrm{p}}=10 \mathrm{~m} / \mathrm{s}$.
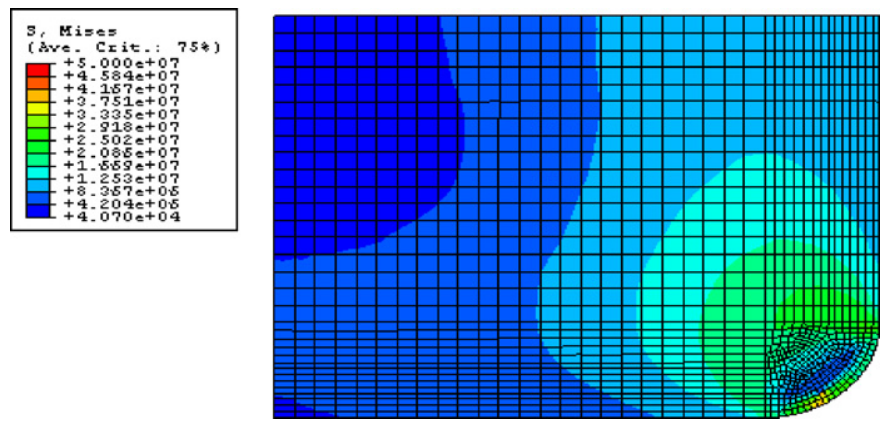

Fig. 10. Distribution of equivalent von-Mises stress in the elastic punch: case where $V_{\mathrm{p}}=1 \mathrm{~m} / \mathrm{s}$.

simulations, by considering the full coupling between elastic tools and parts, with dynamic explicit scheme, imply strong practical difficulties:

(i) It would be necessary to use hundreds of thousands or even more elements in the FE model.

(ii) In order to obtain an accurate solution, it is necessary to noticeably reduce the punch speed involving massive and unacceptable computational times.

Based on these difficulties, it is therefore relevant to decouple the simulation of the blank forming and the linear elastic

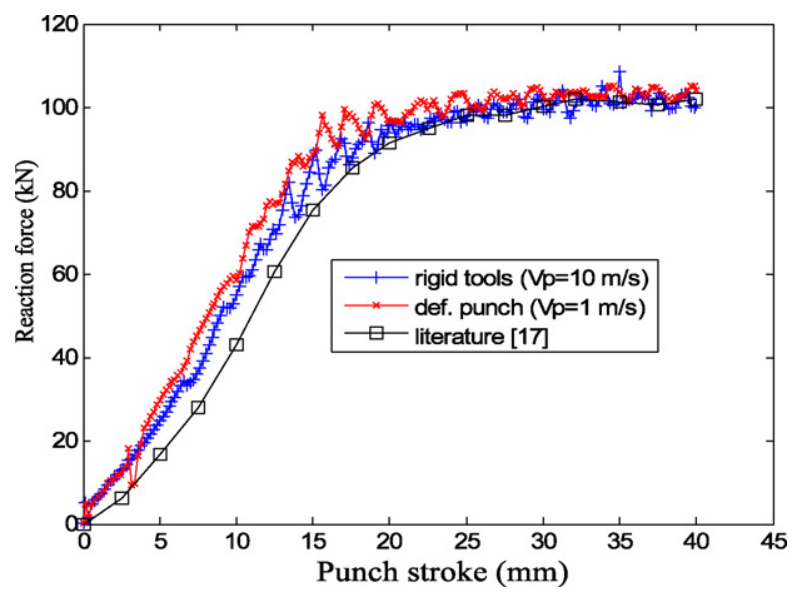

Fig. 11. Punch force-displacement curves: comparison between rigid and elastic tools (dynamic explicit scheme). 
analysis of the tools. Thus, the 3D stress analysis of the tools can be performed separately by exploiting the knowledge of the distribution of the contact forces acting on the rigid tools during the forming operation.

\section{Description of the proposed method}

\subsection{Principle and assumptions}

The contact forces acting on the rigid tools during the forming operation have been found almost identical to those acting on the real standard steel tools (see Section 3). Hence, the stress analysis of tools can be performed using the classical stamping simulation approach by considering rigid tools and by exploiting the knowledge of the distribution of the resulting contact forces. Thus, our procedure involves two separate steps (Fig. 12):

(i) Step 1. The stamping simulation is first conducted classically by considering rigid tools, allowing to obtain an estimation of the distribution of the contact forces acting on the rigid tools during the forming operation;

(ii) Step 2. The stamping tool (layered or not) is analyzed separately by considering its elastic deformation and by applying the distribution of the contact forces computed previously (in step 1) and considered as static external load.

In the present study, the STAMPACK finite element code and the CATIA V5 finite element module were used to perform the steps 1 and 2, respectively.

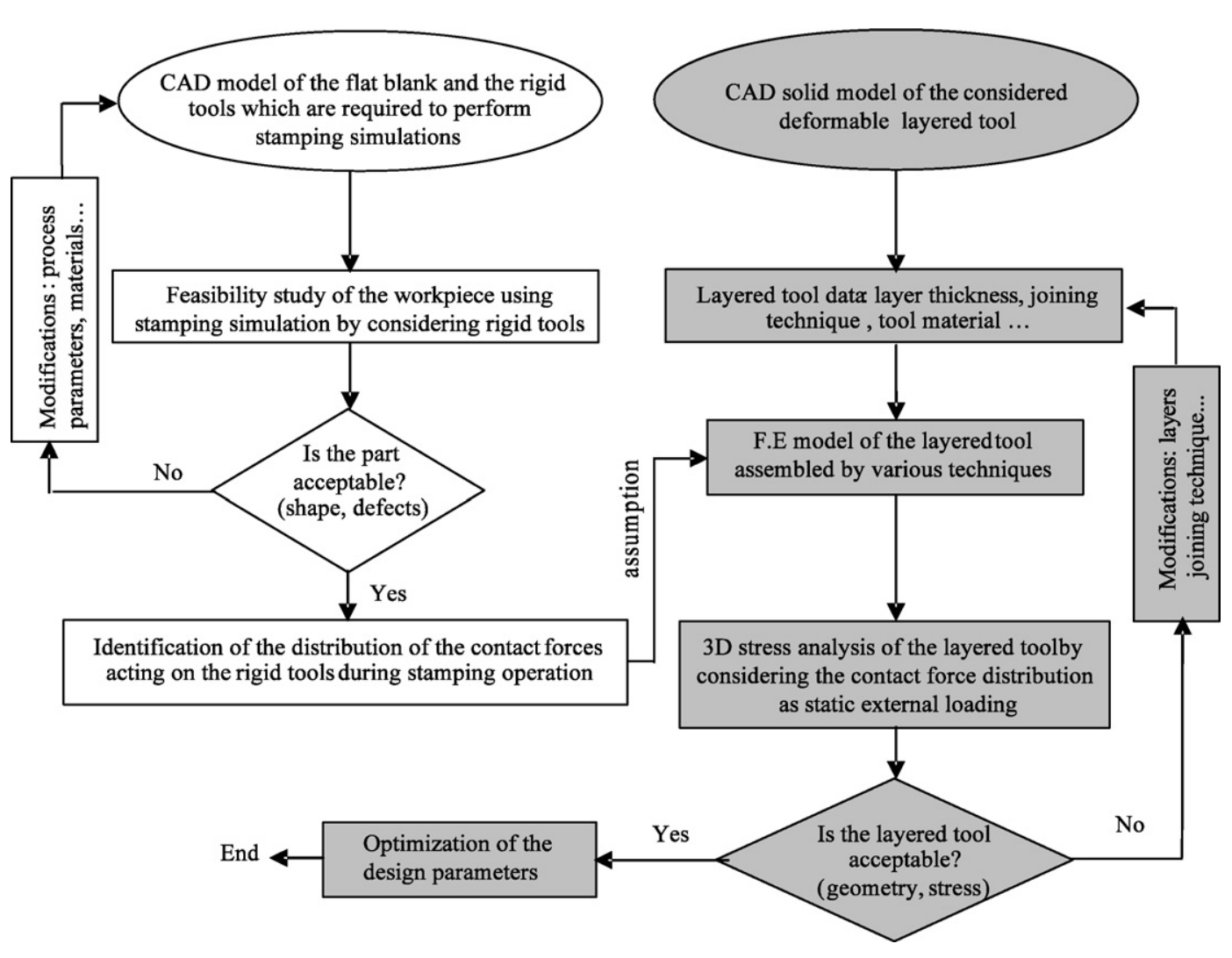

Fig. 12. Procedure for the 3D FE analysis and the design of deformable forming tools. ones.

\subsection{Estimation of the contact forces} follows:

$F^{(i)}=\sum_{j=1}^{\text {nnd }} F_{j}^{(i)}$ in "Set" $(i)$. force, denoted $F_{\mathrm{Z}}$, can be expressed as follows:

$F_{Z}=\sum_{i=1}^{\text {nset }} F_{z}^{(i)}$ parts.

The above procedure, in two steps, is based on the assumption that the contact forces acting on the rigid tools are almost identical to those acting on the real steel deformable

In the beginning of the step 1, the surface of the rigid tool (active tool parts) is divided into small sectors called "Sets" (Fig. 13). For each "Set" (i), the global nodal contact force vector, with its three cartesian components, is automatically computed in STAMPACK [18] and can be expressed as

with $F^{(i)}=\left(F_{x}^{(i)}, F_{y}^{(i)}, F_{z}^{(i)}\right)$, where nnd is the number of nodes

The third component $F_{z}^{(i)}$ represents the vertical punch reaction force acting on the "Set" $(i)$. Then, the total punch reaction

where nset is the number of sectors (or "Sets") in the active tool 


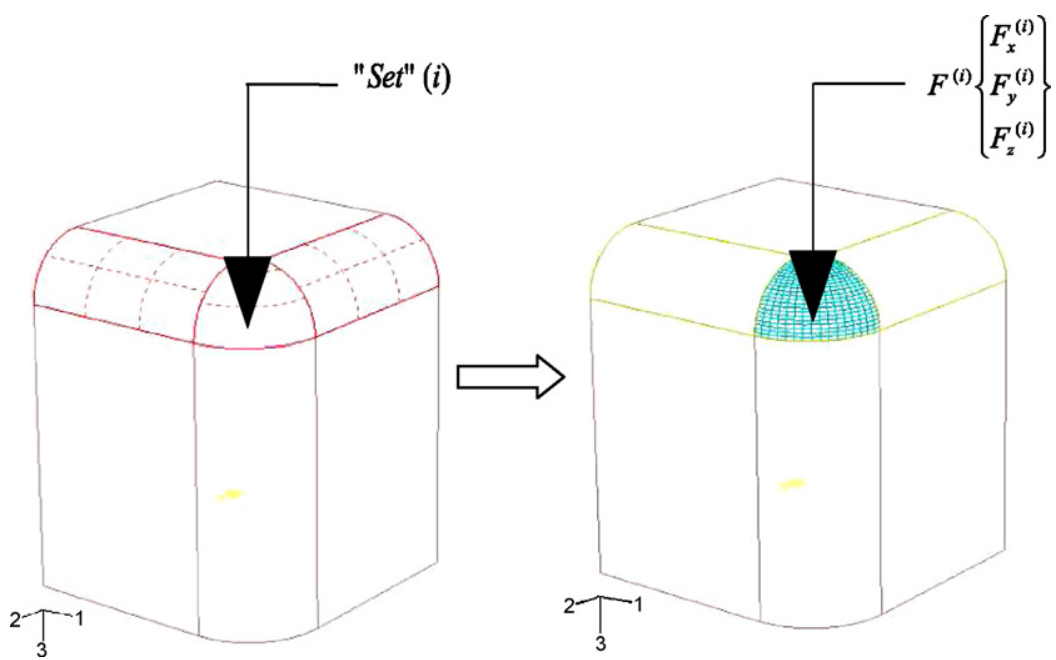

Fig. 13. Schematization of elementary "Sets"/corresponding contact force vector.

\subsection{Equivalent static external load}

In order to simplify the transfer of the distribution of the contact forces from the rigid tool to the deformable one (layered or not), the elementary force vectors $F^{(i)}$ computed previously, in step 1, for each "Set", are automatically replaced (by considering their three cartesian components) by a system of equivalent static loads $P^{(i)}$, distributed according to the following relation:

$F^{(i)}=\iint_{s} P^{(i)} \mathrm{d} s^{(i)}$

where $\mathrm{d} s^{(i)}$ is the area of the elementary "Set" number $(i)$.

The above procedure has already been validated in [12] in the context of simple deep-drawing geometries. The obtained results showed that this procedure gives fairly good stress and strain estimations in the tools compared to that obtained in the context of deep-drawing simulation taking into account elastic deformation of tools, using the ABAQUS static implicit code.

\section{Application to the layered tools: 3D case study}

The benchmark test resulting from the Craft European project Fastool was considered as the example of the application. According to the procedure illustrated in Fig. 12, two separate steps of analysis are required to make $3 \mathrm{D}$ stress analysis of the tool.

\subsection{Step 1: classical stamping FE-analysis}

In the finite element model, a mesh of three-nodes BST shell elements was used in the full model of the blank involving 382518 elements, while the other tools (punch, die and blankholder) were assumed rigid. The blankholder force was $50 \mathrm{kN}$, punch stroke was $50 \mathrm{~mm}$. The material data are: isotropic elasto-plastic behaviour with isotropic hardening given by Hollomon's model with the following material constant: $n=0.23$, $k=522.4 \mathrm{MPa}, E=210 \mathrm{GPa}, v=0.3$.
The contact formulation is based on the masterslave contact approach. The tools are considered as the master surfaces and the sheet is the slave surface. The Coulomb friction model was adopted with a frictional ratio $\mu=0.1$ and the interaction between the sheet and the tools is formulated using the finite sliding approach, which allows the separation of the two surfaces during sliding.

First, some results with regard to the feasibility of the blank forming (shape, strain, stress, thickness distribution) were examined [12]. The obtained workpiece final shape (Fig. 14) is in agreement with the experimental one (Fig. 4).

Second, simulations were run in order to obtain an estimation of the distribution of the contact forces acting on the rigid punch during the stamping operation.

Fig. 15 shows the contact pressure distribution on the rigid punch at the end of the forming stage. It can be seen that the contact forces are mainly located along the punch radius (active parts). This result is in good agreement with the literature [3,12,14-16].

\subsection{Step 2: modelling and FE-analysis of the punch}

In this second step of simulation, the layered punch was analysed separately from the step 1. As shown in Fig. 16, the

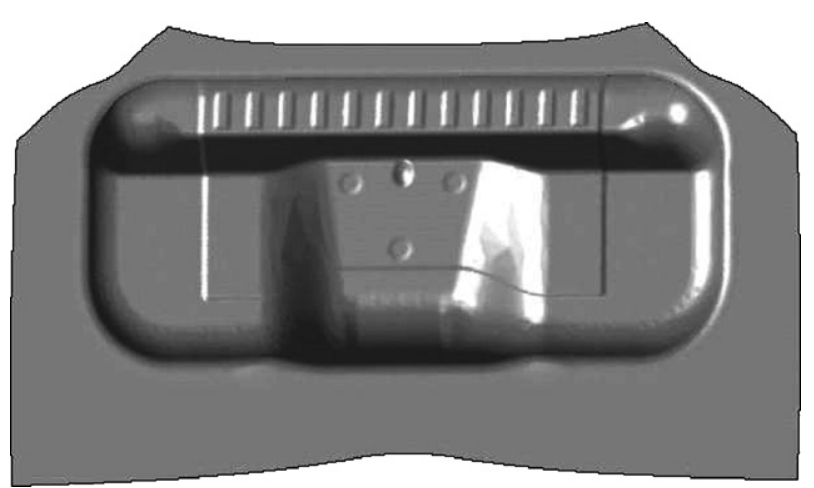

Fig. 14. Workpiece final shape (STAMPACK)/comparison with experiments. 


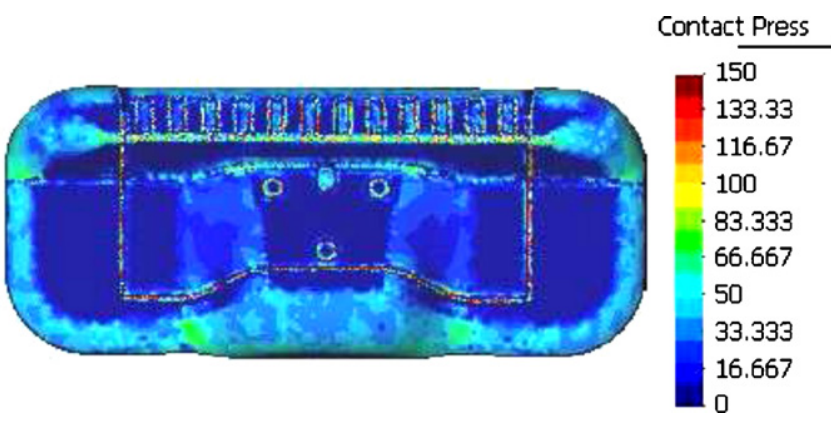

Fig. 15. Contact pressure distribution on the rigid punch surface (STAMPACK).

punch CAD model was generated in CATIA V5 and sliced into $7 \mathrm{~mm}$-thick elementary layers to be consistent with the real one.

The joining technique consists of two plugs $\left(\mathrm{G}_{1}\right.$ and $\left.\mathrm{G}_{2}\right)$ and five screws $\left(\mathrm{S}_{1}-\mathrm{S}_{5}\right)$, in addition to an epoxy adhesive.

The finite element model involves 210124 four-nodes tetrahedral elements with a mesh refinement in the vicinity of the screw holes.

The 2C45 (XC48) steel layers are elastic and isotropic with the following properties: $E=210 \mathrm{GPa}, v=0.3$.

The adhesive with thickness of $0.1 \mathrm{~mm}$ was not modelled in details but each interface between the steel layers is clearly identified in the 3D FE model. As a first assumption for this study, the nodes at the interfaces belonging to the layers are tied leading in fact to a continuous medium. Attention is then paid at the post-processing stage to the maximum tensile and shear stresses which are compared with the corresponding admissible yield stresses of the adhesive. If the stress levels are satisfactory, then sliding or separation of the layers is not possible. Of course the role of the adhesive on layers assembled by screws is important as mentioned in $[12,19]$ but its precise evaluation is considered beyond the scope of the present study and should be addressed in a future research paper.

The loading conditions are as follows:

(i) The initial clamping state. This stage is automatically generated in CATIA V5, by assuming minimal clamping force of $6000 \mathrm{~N}$ for each screw.

(ii) The forming load. The distribution of the contact forces, provided by the numerical simulation, in step 1, is automat-

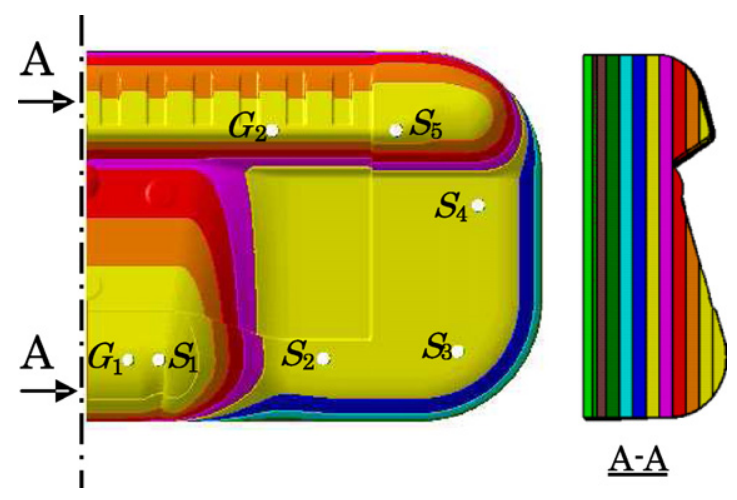

Fig. 16. CAD model of the layered punch (CATIA V5). ically imported in CATIA V5 and applied to the layered punch FE model as static load.

\section{Results and discussions}

The stress and strain distributions in the layered punch have already been investigated in [12] and it was found that the joining technique by screws requires more attention and plays an important role in the design decision of layered tools. Thus, we focussed on what happens in the screws, under the forming load.

When the distribution of the contact forces (due to the stamping) is applied to the layered punch, which is joined with an initial clamping force $\left(F_{\mathrm{s}}\right)_{\mathrm{i}}$, increments (variations) $\Delta F_{\mathrm{s} j}$, in the axial screw forces, are produced. Fig. 17 shows the increments in the axial screw clamping forces as a function of the axial forming load $F_{Z}$. It can be seen that the increments $\Delta F_{\text {s } j}$ occurring in axial screw forces increase linearly with the increase of the forming load (contact forces). This result is in agreement with the literature [19].

From Fig. 17, it can be seen that the highest values of increments are produced in screws $S_{1}$ and $S_{5}$, while the increment values in the other screws are not significant. This can be explained using the theoretical relationship between the increment and the axial forming load, occurring in each screw, which can be expressed as follows:

$\Delta F_{\mathrm{s}}=\left[\left(F_{\mathrm{s}}\right)_{\mathrm{i}}-\left(F_{\mathrm{s}}\right)_{\mathrm{f}}\right]=\frac{K_{\mathrm{t}}}{K_{\mathrm{t}}+K_{\mathrm{cg}}}\left(\frac{K_{\mathrm{cg}}^{\prime}}{K_{\mathrm{pt}}}\right) F_{Z}$

The quantity $\phi=\left(K_{\mathrm{t}} /\left(K_{\mathrm{t}}+K_{\mathrm{cg}}\right)\right)\left(K_{\mathrm{cg}}^{\prime} / K_{\mathrm{pt}}\right)$, is called the screw load factor.

$K_{\mathrm{t}}[19]$ is the spring constant for a screw system and $K_{\mathrm{cg}}$ [19] is the compressive spring constant for a layer around a screw hole. $K_{\mathrm{cg}}^{\prime}$ and $K_{\mathrm{pt}}$ are the compressive spring constants defined using the mean displacements produced in the screw holes when the initial clamping force and the stamping load are respectively

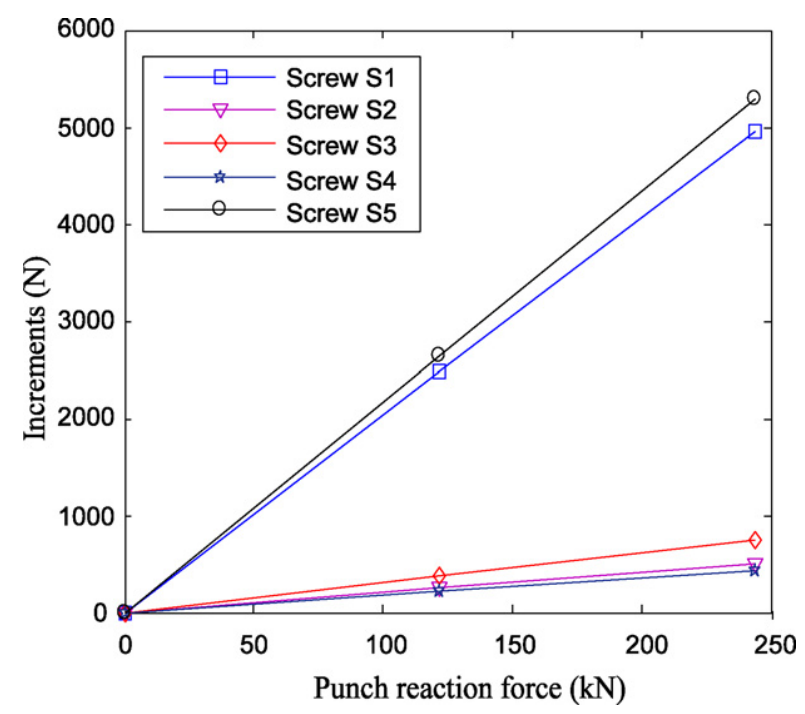

Fig. 17. Increments (variations) in initial axial screw forces as a function of the stamping load (punch reaction force). 
acting. $\left(F_{\mathrm{S}}\right)_{\mathrm{i}}$ and $\left(F_{\mathrm{s}}\right)_{\mathrm{f}}$ are respectively the initial and the final axial screw forces.

The slopes of $\Delta F_{\mathrm{s} j}$ (Fig. 17) are independent of the initial clamping force $\left(F_{\mathrm{s}}\right)_{\mathrm{i}}$ and can be used in order to obtain the individual screw load factors.

On the other hand, it is found that the value of $\left(F_{\mathrm{S}}\right)_{\mathrm{f}}\left(=\left(F_{\mathrm{S}}\right)_{\mathrm{i}}+\Delta F_{\mathrm{S}}\right)$, in each screw, decreases because the value of $\Delta F_{\mathrm{s}}$ is negative.

In such screwed joint, the initial pre-stressed screws should remain in tension under the loading conditions, for a proper strength of the joint. Hence two problems, related to this joining technique, can be identified:

(i) The decrease in the initial clamping force, due to the forming load, is not allowed when the final screw clamping force tends to zero (this can leads to screw loosening);

(ii) The increment occurring in the axial screw clamping force can leads to large force increments in the screws, which can greatly affect the fatigue behaviour (inducing cyclic stress in the screws). The cyclic stress in each screw can be expressed as follows:

$$
\sigma_{\mathrm{cycl}}=\frac{\left(F_{\mathrm{s}}\right)_{\mathrm{i}}-\left(F_{\mathrm{s}}\right)_{\mathrm{f}}}{2 A_{\mathrm{s}}}=\frac{\Delta F_{\mathrm{s}}}{2 A_{\mathrm{s}}}
$$

where $A_{\mathrm{s}}$ is the cross-section of the screw.

Based on these remarks, it appears then necessary to reduce the increments occurring in axial screw clamping forces, due to the forming load, in order to improve the strength and the life duration of the joining technique. This can be achieved by optimizing the positions of the screws.

\section{Optimization of the screw positions}

\subsection{Formulation of the optimization problem}

Here, only the screw positions $P_{j}$ are considered as the design variables. The final objective is to obtain in a layered punch in which the increments occurring in the axial screw forces are as small as possible. Each screw position $P_{j}$ is then defined by the cartesian coordinates $\left(x_{j}, y_{j}\right)$ of the screw hole center, leading to two design variables per screw.

\subsection{Cost function}

The cost (or objective) function we consider in this paper is defined in terms of the increments occurring in the axial screw forces, such that:

$F=\frac{1}{\mathrm{~ns}} \sum_{j=1}^{\mathrm{ns}}\left[\Delta \sigma_{\mathrm{s} j}\right]^{2}=\frac{1}{\mathrm{~ns}} \sum_{j=1}^{\mathrm{ns}}\left[\left(\sigma_{\mathrm{s} j}\right)_{\mathrm{i}}-\left(\sigma_{\mathrm{s} j}\right)_{\mathrm{f}}\right]^{2}$

where $\Delta \sigma_{\mathrm{s} j}=\left(F_{\mathrm{s} j}\right)_{\mathrm{i}}-\left(F_{\mathrm{s} j}\right)_{\mathrm{f}} / A_{\mathrm{s} j}$ is the pre-stress variation in screw $j$, expressed as a function of initial and final axial screw forces $\left(F_{\mathrm{s} j}\right)_{\mathrm{i}}$ and $\left(F_{\mathrm{s} j}\right)_{\mathrm{f}}$, and the screw cross section $A_{\mathrm{s} j}$. ns is the screw number.

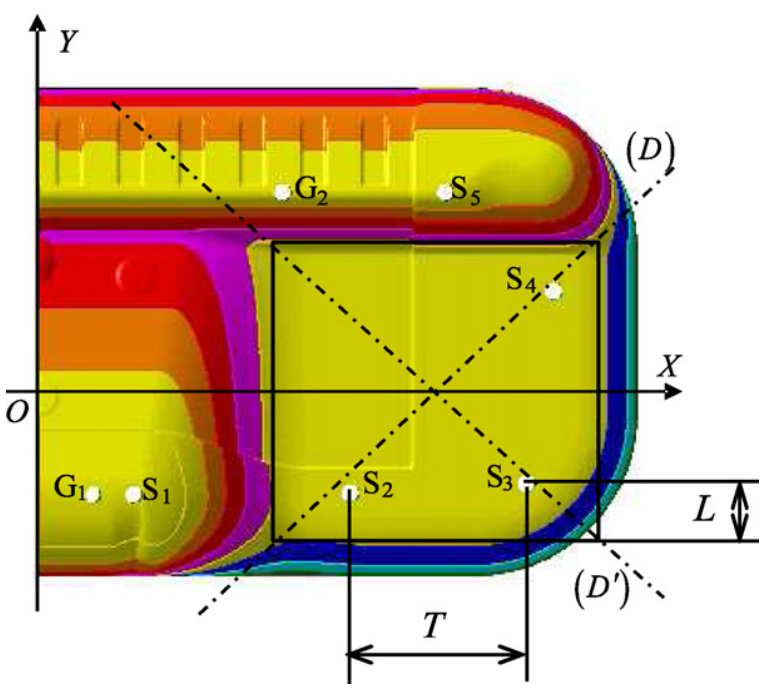

Fig. 18. Illustration of the design constraints.

A normalized form of Eq. (6) is defined as follows:

$f_{\text {cost }}=\frac{F-F_{\min }}{F_{\max }-F_{\min }}$

\subsection{Design constraints}

The research domain of the design variables is bounded to satisfy the design rules of screwed joints [20]. For example, the distance $T$ between screw axes, and the distance $L$ between screw axes and outside edge of layers (Fig. 18) are closely related to the screw diameter $d$. These feasibility constraints can be expressed as inequality relations [20]:

$G=\left\{\begin{array}{l}1.5 d \leq L \leq 3.5 d \\ 3.5 d \leq T \leq 7 d\end{array}\right.$

where $d$ is the screw diameter.

\subsection{Optimization strategy}

To solve the optimization problem, computations based on the design of experiments (DoE) technique were conducted and coupled to an optimization method in Matlab. The initial optimization problem based on the DoE with five screws leading to 10 design variables involves $2^{n}+2 n+1=1045(n=10$ design variables) FE-analyses in CATIA V5 (if the central composite DoE with three levels for each variable is considered). However, the effort and experimental cost required for such a design could be prohibitive and unrealistic. In order to reduce the size of the problem (the number of design variables), we did adopt the following strategy:

(i) First, the displacements of the screws $\mathrm{S}_{1}$ and $\mathrm{S}_{5}$ in the $Y$ direction are eliminated because of the small width of the layers (Fig. 18);

(ii) Second, the screws $\mathrm{S}_{2}, \mathrm{~S}_{4}$, and $\mathrm{S}_{3}$ are restrained to move respectively according to the $(D)$ and $\left(D^{\prime}\right)$ axes. 
Table 1

Initial and final parameters

\begin{tabular}{lll}
\hline & Initial & Final \\
\hline$f_{\text {cost }}(\%)$ & 100 & 73 \\
$P_{1}\left(x_{1}, y_{1}\right)$ & $(35,-56)$ & $(35,-56)$ \\
$P_{2}\left(x_{2}, y_{2}\right)$ & $(115,-55.5)$ & $(110,-53.5)$ \\
$P_{3}\left(x_{3}, y_{3}\right)$ & $(180,-52)$ & $(178.2,-42)$ \\
$P_{4}\left(x_{4}, y_{4}\right)$ & $(190,19)$ & $(186.5,15.8)$ \\
$P_{5}\left(x_{5}, y_{5}\right)$ & $(148,55.5)$ & $(112,55.5)$ \\
\hline
\end{tabular}

Thus the problem is reduced to five design variables (one variable per screw). In addition, preliminary simulations show that the optimization problem can be transformed in two separate sub-problems since it is found that there is no interaction between the positions of screws $\mathrm{S}_{1}$ and $\mathrm{S}_{5}$ with the other ones. Thus the initial optimization problem can be conducted in two steps:

(i) Step 1. The positions of screws $\mathrm{S}_{1}$ and $\mathrm{S}_{5}$ are first optimized (optimization step with two design variables).

(ii) Step 2. The positions of screws $\mathrm{S}_{2}-\mathrm{S}_{4}$ are then optimized (optimization step with three design variables).

\section{Optimization results}

As shown in Table 1, the developed optimization procedure allows to noticeably reduce the individual screw pre-stress increments, due to the forming load. In this case study, the minimization of the cost function $\left(f_{\text {cost }}\right)$ reaches $27 \%$.

\section{Conclusion}

In this paper, a simplified numerical procedure for the $3 \mathrm{D} \mathrm{FE}$ analysis of deformable stamping tools is proposed and discussed with particular attention to the analysis of layered tools joined by adhesive and screws. The stress analysis procedure is based on the decoupling of the simulation of the blank forming with the elastic analysis of the deformable tools.

The adhesive is not fully considered in the present analysis, but the stress field is particularly analyzed at the layer interfaces to check the validity of the assumption of material continuity.

The numerical approach has been applied on the industrial application of a layered punch designed and manufactured using the Stratoconception ${ }^{\circledR}$ system. The following remarks can be mentioned:

(i) The decrease in screw pre-stresses are highly related to the stamping load and also to the spring constants of the joined layers around the screw holes. It is then advisable to reduce these decreases, as much as possible, by considering both appropriate screw positions and minimum allowable height of the layered tooling;

(ii) The initial clamping force must be considered as an important parameter to guarantee minimal tensile force in axial screws when the decrease in axial screw force is large; (iii) The decrease in axial screw forces can lead to large stress increments (or variations) in the screws, which can affect the fatigue behaviour.

In order to improve the design of the layered forming tools joined by screws, an optimization procedure has been proposed to optimize the screw positions. The results show its ability to reduce the force increments occurring in each screw, due to the forming load.

More detailed research works can be proposed such as

(i) Advanced modelling of the layer interfaces to estimate more precisely the role of contact with friction and adhesive material on the compliance and the 3D stresses in the layered tooling and screws.

(ii) Influence of inertia forces, vibrations and fatigue on the behaviour, integrity and life duration of the non-standard layered tools.

\section{Acknowledgments}

The authors would like to thank: Dr. A. Delamézière from ERMeP/GIP-InSIC for the fruitful discussions regarding the Design of Experiments and the response surface method; Dr. Laurentiu Neamtu from Quantech ATZ (Spain) for the helpful discussions regarding the use of the STAMPACK finite element code; CIRTES Company for providing informations on the Craft European Project Fastool.

\section{References}

[1] T. Nakagawa, Advanced in prototype and low volume sheet forming and tooling, J. Mater. Process. Technol. 98 (2000) 244-250.

[2] D.H. Mueller, H. Mueller, Rapid Prototyping Techniques to Manufacture Sheet Metal Forming Tools, ISATA, Dublin, Ireland, 2000.

[3] M. Oudjene, J.-L. Batoz, F. Mercier, L. Penazzi, C. Pelaingre, Mechanical analysis of prototyping tools for sheet metal stamping, in: Proceedings of RPD2004 Advanced Solutions and Development, Marinha Grande, Portugal, October 12-13, 2004.

[4] H. Muller, J. Sladojevic, Rapid tooling approaches for small lot production of sheet metal parts, J. Mater. Process. Technol. 115 (2001) 97-105.

[5] D.F. Walczyk, D.H. Hardt, Design and analysis of recomfortable discrete dies for sheet metal forming, J. Manuf. Syst. 17 (6) (1998) 436-454.

[6] D.F. Walczyk, D.H. Hardt, Rapid tooling for sheet metal forming using profiled edge laminations - design principles and demonstration, J. Manuf. Syst. 120 (1998) 746-754.

[7] D.F. Walczyk, D.H. Hardt, A comparison of rapid fabrication methods for sheet metal forming dies, J. Manuf. Syst. 121 (1999) 214-224.

[8] P.M. Dickens, Principles of design for laminated tooling, Int. J. Prod. Res. 35 (N5) (1997) 1349-1357.

[9] C. Abel, L. Velnom, C. Barlier, P. Poirier, FASTOOL et MOLSTRA; Deux projets européens de recherche collaborative en PME (CRAFT)-Intégration du procédé de Stratoconception ${ }^{\circledR}$ en outillage rapide direct pour l'injection, l'emboutissage et la fonderie sous pression, Micad 2003, Paris, avril 1-3, 2003.

[10] B. Wadman, Fluid cell forming tools produced by different rapid prototyping methods, in: Proceedings of the 22th International Deep Drawing Research Group Congress, Bled, Slovenia, 2003, pp. 205-214.

[11] M. Oudjene, F. Mercier, L. Penazzi, J.-L. Batoz, 3D finite element modeling and analysis of the laminated tooling behaviour in sheet metal stamping process, in: Proceedings of the 24th International Deep Drawing Research Group Congress, Besanon, France, June 20-22, 2005, p. 10. 
[12] M. Oudjene, Modélisation et optimisation du comportement mécanique des outils d'emboutissage stratifiés précontraints par vissage, Ph.D. Thesis, Institut National Polytechnique de Lorraine, Nancy, France, 2005.

[13] T. Pepelnjak, K. Kuzman, Adaptable tooling sets for metal forming of geometrically similar products, J. Mater. Process. Technol. 80/81 (1998) 413-420.

[14] J. Dankert, Reduction of the residual stresses in a deep-drawing cup by modifying the draw die profile, Ann. CIRP 44/1 (1995).

[15] F.F. Damborg, M.R. Jensen, K.B. Nielsen, J. Dankert, Optimization of the draw die profile with regard to wear using the FEM, in: Proceedings of the 19th International Deep Drawing Research Group Congress, Eger, June 10-14, 1996.

[16] M. Burlat, Analyse Mécanique et Tribologique de l'Emboutissage: application aux Outils fabriqués par combinaison de différents matériaux, Ph.D. Thesis, Institut National des Sciences Appliquées de Lyon, 1998.
[17] A. Makinouchi, E. Nakamachi, E. Onate, R.H. Wagoner (Eds.), Proceedings of the 2nd International Conference Numerical Simulation of 3-D Sheet Metal Forming Processes-Verification of Simulation with Experiments (Numisheet'2002), Isehara, Japan, 31 August-2 September, 2002.

[18] A.T.Z. Quantech, Stampack User Guide-Version 5.6, Quantech edt., Edificio Nexus, Gran Capitn, 2-4, 08034, Barcelona, Spain, 2004.

[19] M. Yoneno, T. Sawa, T. Ishihara, The strength of joints combining adhesives with bolts (case where adherends are pipe flanges of which the interfaces are bonded partially), JSME Int. J., Ser. A 42 (1) (1999) 126134.

[20] Centre Technique Industriel de la Construction Métallique, Régles de calcul des constructions en acier "Régles CM66", Editions Eyrolles, 11éme édition, 1995.

[21] http://www.cirtes.fr. 